\title{
Public Health Expenditure and Child Mortality Rate as Determinants of Full Immunization Coverage and Poverty Rates in Cameroon
}

\author{
Promise Aseh Munteh ${ }^{1 *}$, Alyce Fri Fonchin ${ }^{2}$ \\ ${ }^{1}$ Assistant Lecturer/Director of Cooperation Catholic University of Cameroon (CATUC), Bamenda, Cameroon \\ ${ }^{2}$ PhD Candidate, Department of Economics Center of Excellence in Reproductive Health Innovation University \\ of Benin, Nigeria
}

\begin{abstract}
*Corresponding Author: Promise Aseh Munteh, Assistant Lecturer/Director of Cooperation Catholic University of Cameroon (CATUC), Bamenda, Cameroon.
\end{abstract}

\begin{abstract}
Under-5 mortality is a continuous health challenge to most Sub-Saharan African countries especially Cameroon. Cameroon, which did not achieved its Millennium Development Goal-4 target of a 2/3 reduction in under-5 mortality rate by 2015 is unlikely to achieve its Sustainable Development Goal-3.2 target of reducing under-5 mortality to at least 25deaths/1000live births despite the implementation of health reform programs such as Integrated Management of Childhood Illnesses and continuous efforts made towards increasing immunization coverage and alleviating poverty. In 2017, under-5 mortality in Cameroon was at 84deaths/1000live births, higher than the Sub-Saharan regional average of 75.5deaths/1000live births and twice the global average of 39.1 deaths/1000live births in the same year. The government of Cameroon has a responsibility of investing into the health sector, which will lead to the country's continual growth. Government health spending in Cameroon which is a major determinant to the country's health outcome, as part of General Government Expenditure, has decreased from 6.2\% in 2010 to about 5.2\% in 2016 which is lower than the 14\% average for low and middle income countries and falls short of the WHO's $10 \%$ recommendation, and the 15\% Abuja pledge, and as a proportion of the GDP (0.9\%) remains one of the lowest in Africa. Nevertheless, empirical evidence on the effect of public health expenditure on under-5 mortality rates in Cameroon has remained questionable. Simple ordinary least squares method was used to investigate the relationship between public health expenditure and under-5 mortality rate for Cameroon in a short run using annual time series data from 2001-2014, factoring in full immunization coverage rates and poverty rates. The results showed that public health expenditure has a negative but insignificant effect on under-5 mortalities when full immunization coverage rates and poverty rates indicators are included. The policy implication is that achieving the SDG-3.2 target in Cameroon may be unattainable if the levels of poverty and immunization coverage rates are not considerably improved upon.
\end{abstract}

Keywords: Public Health expenditure, child Mortality, immunization, poverty.

\section{INTRODUCTION}

Health is a fundamental aspect of life, because poor health affects an individual's capacity to enjoy life, produce and consume other valuable goods and services. Due to this vitality of health, global health reforms are continuously been carried out to ensure universal health coverage is a reality. The World Health Organization (WHO, 2012) stated that, health is central to development. Because a healthy population status leads to an increase in life expectancy, low mortalities especially among children and adolescents, and thus increases productivity amongst others. Unfortunately this is not the case for most Low and Middle Income Countries (LMICs). In the past 20 years,
Cameroon for instance has witness a decline in mortalities rates of all ages. Unfortunately, this decline did not result in the country achieving its Millennium Development Goal-4 (MDG-4) objective of reducing under-5 mortality by twothirds by 2015 even though at the inception of the Millennium Development Goals (MDGs) Cameroon equipped itself with a "vision 2035" and Health Sector Strategy for 2016-2027 in between, aimed at re-assuring universal access to quality healthcare services for all social groups by 2035 with the full participation from communities (WHO, 2018).

Under-5 mortality has declined by about $54 \%$ (from 172/1000 to 80/1,000 children) between 1998 and 2016 respectively. However, child 
mortality is still quite high (84 deaths/1000 live births, higher than the sub-Saharan regional average of 75.5/1000 and twice the global average of 39.1 deaths/1000 live births in 2017), registering great regional disparities, with the Northern and Eastern regions performing worse than the national averages (WHO, 2018). This under performance is a sharp contrast to Cameroon's economic status and the relatively high per-capita health spending of about \$138 in 2014 (World Bank, 2018). In addition, despite the reduction in the overall health budget of Cameroon as a result of a fiscal consolidation, as part of the investment plan,the Ministry of Public Health reports a substantial increase in the health budget allocation to priority regions identified as being high-burdened, but hardly has this budget been translated to positive health outcomes(Pacific Prime, 2019).

Health systems around the world are diverse. And this diversity is widely seen in the differences in their health expenditures. Although health expenditures can affect health outcomes, the efficiency with which countries are able to translate their health care spending into better health outcomes varies significantly due to the diversity in health systems. Hence, the relationship between public health expenditure (PHE) and national health outcome is a continuous debate with the exact nature of this relationship still uncertain (Kim \&Lane, 2013). Over the years, public health expenditure (\% of the GDP) in Cameroon has increased from 0.93 in 2000 to 1.51 in 2010 but this increase has not been translated into corresponding increase in health outcomes. Cameroon has witnessed very slow improvements in its health indicators (World Bank, (WB) 2019).

According to Grossman (1999) health production function, health outcomes depends on many variables besides the price for medical care which include socio-economic and environmental factors amongst others which are continuously been discussed as important aspects of health care reforms globally. In this regard, Muthaka (2013), identified immunization as one of the most important inputs to health production as it has a direct impact on child health outcome indicators. Till date, $\operatorname{WHO}(2017)$ identifies immunization as one of the most effective global public health interventions to ensure child survival. And as a result of immunization, there has been a global decline of child killer diseases like measles by
$85 \%$ and $89 \%$ in Sub-Saharan Africa between 2000 and 2016 respectively, and the world is closer than ever to eradicating polio (UNICEF, 2018). Immunization in Cameroon is done through the Expanded Programme on Immunization (EPI) which first began in Cameroon in 1976. Over the years, full immunization coverage rate in Cameroon has improved from $48.0 \%$ in 1986 to $75.9 \%$ in 2013. However, the coverage rates differ in some regions compared to others with some particular vaccines having more coverage rates than others and full nationwide coverage rate is still below the $80 \% \mathrm{WHO} / \mathrm{UNICEF}$ coverage rate target (WHO \&UNICEF, 2017).

The Addis Abba declaration (2006) and the global commitment towards universal access to health care acknowledged the relationship between health and alleviation of the widespread poverty challenges that still remains in the African continent to enable the realization of the MDGs. In addition, Victorino\& Gauthier (2009) stated that the socio-economics status notably, income level is the most frequently assessed social determinant in child health research. Further, Moore, McDonald, Carlon\& O'Rourke (2015) using a wide range of indicators pertaining to children and families' health outcomes, showed that health outcomes for children and families are better-off for individuals of better socioeconomic status and worsen progressively the further down as they move, with children's health and development determined by the circumstances in which the children are born, which include poverty, amongst others. Over the years, there has been a slight global decline in poverty rates as seen in 2015 where $10 \%$ of the world's population lived on less than US\$1.90 a day, compared to $11 \%$ in 2013.

This is about $36 \%$ difference from the 1990 's. Despite the global decline in poverty rates in all regions, the number of people living in extreme poverty globally still remains unacceptably high. East Asia and Pacific, Europe and Central Asia have achieved the 2030 target of reducing extreme poverty to below $3 \%$, whereas more than half of the extremely poor people live in Sub-Saharan Africa with an increase number of 9million poor people in this region and 413 million people living on less than US\$1.90 a day in 2015 (WB, 2019). In Cameroon, the poverty rate at national poverty line fell gradually from $53.3 \%$ in 1996 to $37.5 \%$ in 2014 (WB, 2019), a development that still 
leaves a great number (5.3 million) of the Cameroonian population below the international poverty line of 467.4CFA franc (2014) or US\$1.90 (2011 PPP) per day per capita (WB, 2019). This poses a limitation for Cameroonians to seek for health care.

The relationship between health expenditure and child mortality has triggered a number of empirical studies for instance: Rajkumar\&Swaroop, (2008); Yaqub, Ojapinwa, $\&$ Yussuff (2012) who used cross country data and national time series data respectively to show that the relationship between public health expenditures and infant and child mortality is governance dependent, Anyanwu\&Erhijakpor (2009) used regional panel data and found a regional dependent relationship between health expenditure and infant/child mortalities, (Issa\&Quattara, 2005), using cross country data showed that this relationship depends on the economic development of the country, and Ndedi, Metha\&Nisabwe (2017) showed that health expenditure is a fundamental determinant for economic growth in Cameroon . In addition, other authors have studied the effect of PHE on child mortality rates (CMR)using country specific data, for instance; Muthaka (2013) established a negative but non-significant effect between government health expenditure and all measures of child health using country level data for Kenya analysed by linear probability and control function models,

Compah-Keyeke, Sackey\&Azinim (2013), used ordinary least squares (OLS) regression on time series data for Ghana and showed that this relationship in a short run was dependent on the number of physician per population and health insurance, Toby \&Arabi (2019) used the OLS and the Breusch-Pagan / Cook-Weisberg test results analysis on time series data for India, Oluwatoyin, Folasade\&Fagbeminiyi (2015) used Johansen Co-integration and the Vector Error Correction Model econometric technique to determine the long-run relationship between public health spending and health outcomes for Nigeria and Kato, Mugarura, Kaberuka, Matovu and Yawe (2018) used OLS techniques and found that recurrent health expenditure, capital health expenditure, women literacy rate and percentage of population living in urban areas are strongly associated with under-five mortality rate in Uganda.

Unlike the above mentioned studies, this paper will contribute to existing literature on the effect of public health expenditure on child mortality rates in Cameroon factoring in full immunization coverage rates and poverty rates (a measure of the poverty head count ratio) using national annual time series data in a short run, empirically analyzing data for Cameroon from 2001-2014 sourced from different sources using OLS regression and 2-stage least square analysis. In this perspective, the following hypothesis are developed for this study (i) an increase in public health spending has no significant effect on child mortality rates in Cameroon, (ii) there is no significant relationship between poverty rates and child mortality rates in Cameroon, and (iii) there is no significant relationship between full immunization rates and child mortality rates in Cameroon. Following the introduction, the remaining part of this study is structured as follows; section 2 presents a review of both conceptual and empirical literature, section 3; the methodology, theoretical framework, model specification and data source, section 4; presentation of results and discussions of findings and lastly section 5; summary, conclusions and recommendations

\subsection{An Overview of Child Health in Cameroon}

UNICEF, (2016) asserted that Cameroon which is a signatory to all the major child protection conventions, is ranks the $18^{\text {th }}$ position of the 20 countries in the world with a high under-5 child mortality rates of about 90.1 death per 1,000 live births and $30 \%$ of births are not registered. Only $13 \%$ of under-5 children sleep under insecticide-treated nets, with malaria accounting for more than $40 \%$ of under-5 mortality. Access to, and utilization of, prevention-of-mother-tochild-transmission (PMTCT) services are limited resulting in HIV infection transmitted to children. Though Cameroon's health sector has registered modest progress in some health outcomes, other indicators have worsened, and overall spending on the health sector continues to be low when compared with other countries. During the MDGs era, Cameroon attempted to reduce its under-5 mortality rate from 138 deaths $/ 1,000$ live births in 1990 to 90.1 deaths/1000 live births in 2015 .

However, the rate fell significantly but did not reach the MDG target of 46 deaths per 1000 live births. About $1 / 3$ of under-5 children suffer from chronic malnutrition, including $13 \%$ who are severely malnourished. Health outcomes and 
the coverage of essential maternal and child health services vary substantially across regions with the Far North, North, Adamawa, and East Regions consistently experiencing the worst outcomes for nearly all infant and child mortality and nutrition indicators with the northern regions having the lowest coverage rates for child immunization, antenatal care, assisted deliveries, and modern family planning. For example, the under-5 mortality rate in the North (173 deaths per 1,000 live births) is more than four times higher than in Yaoundé (42 deaths per 1,000 live births).

\subsection{Public Health Care Expenditure in Cameroon}

The World Bank (2018) asserted that the annual Gross Domestic Product (GDP) growth rate of Cameroon was at $3.2 \%$ in 2017, the lowest rate in seven years, and the fiscal deficit peaked at $6.1 \%$ in 2016. Meanwhile, there was a significant increase in borrowing to fund projects which pushed the debt-to-GDP ratio from $15.9 \%$ of GDP in 2006 to $35.7 \%$ of GDP in 2017. This has led to great divergence from the Vision 2035 targets of several key socioeconomic indicators including maternal and child health outcomes. Hence, government spending on health is low and declining as a share of the total national budget and the government health spending as a proportion of total expenditure and GDP $(0.9 \%)$ remains one of the lowest in Africa. As a part of General Government Expenditure (GGE), public health spending has decreased from $6.2 \%$ in 2010 to an estimated $5.2 \%$ in 2016 which is much lower than the $14 \%$ average for LMICs and falls short of the WHO recommendation of $10 \%$, and the 15\% Abuja declaration pledge. This suggests that, over the last 7 years, health sector spending has not been a priority in the budgeting decisions of Cameroon. This is detrimental to the Cameroonian population that has $40 \%$ of its inhabitants living below the poverty line with low human development indicators (World Food Program, 2018).

\section{REVIEW OF RELATED LITERATURE}

This section is divided in to two; the conceptual literature and the empirical literature.

\subsection{Conceptual Literature}

\subsubsection{Public Health Expenditures}

The WHO (2014) asserted that financing health care is fundamental to health system development especially in the African region where appropriate health care financing will improve access to health care services and enable achievements of the health related then MDGs and the now Sustainable Development Goals (SDGs).The WHO (2010), stated that over the years, health care expenditure in developing regions has been low as most of these countries rely on unsustainable and inadequate grants and loans to address the enormous health burden in the region. But in 2018, the WHO showed a transformation course for global spending on health with increasing domestic public funding and declining external financing for all WHO Member States between 2000 and 2016. Just like funding health care services differ globally, health spending also differs. (Poullier, Hernandez)

Kawabata \&Saved off, (2002) using the National Health Accounts methods for the Organization for Economic Co-operation and Development (OECD) countries and statistical yearbooks, national and international health care spending report methodology for non-OECD countries for all WHO 191 states, showed that high income countries spend a greater share of their income on health care and countries that spend little on health care services are faced with poor health conditions. This is supported by the study of (Maruthappu, Bonnie, Williams, Atun\&Zeltner, 2014), who useda comparative country-level data for 176 countries from the year 1981 to 2010, and a multivariate regression analytical method and found that a reduction in government health spending was associated with significant increases in child mortality especially in low-income countries. Hence, Countries with high level of public health spending have secured better health outcomes compared to countries with low level of public health spending. This means that, the size of the public fund in the health sector matters for better health outcomes.

\subsubsection{Child Mortality}

UNICEF (2018) defines child mortality as the death of children under the age of 14. It encompasses national mortality of the number of younger children (under-5years) who die before the age of 5years per 1000 live births and the number of older children between the age 514years who die per 1000 live births in this age range. But more typically child mortality is often referred to as the under-five mortality. Byaro and Musonda, (2017), stated that the 
health outcome of a nation symbolizes the health of its population and under-five mortality rates are global indicators of child health as well as of population health. Hence, child mortality rate which is the most important indicator for early childhood development and health status of population for a given country (Franz \&FitzRoy, 2006) is used in this study. According to UNICEF (2013), the highest rates of child mortality are still in Sub-Saharan Africa where 1 in 9 children dying before the age of five is more than 16 times the average for developed regions (1 in 152). Further, (UNICEF, 2018), stated that over the past few years, there have been noticeable changes in child survival with millions of children having better survival chances in 2017 where globally, 1 in 26 children died compared to 1990s when 1 in 11 children died before reaching age 5years. Despite this global reduction in child mortality over the years, an estimated 5.4 million children under age 5years died in 2017 with about half of these deaths still occurring in Sub-Saharan Africa.

\subsubsection{Public Health Expenditure and Child Mortality}

Taking into consideration the complexity of what determines health outcomes (child mortality), it will be partial to conclude that there is a direct positive or negative relationship between public health expenditure and child mortality. (Kim \& Lane 2013; Kulkarni 2016), stated that the relationship is complex, owing to the involvement of a diversity of factors in the health care production function. Hence, research shows a mix of results, with an expansion of public health expenditure improving child mortality in some cases whereas it is ineffective in other cases. Public health spending most often does not occur in a vacuum. A combination of others factors needs to exist for public health spending to be effectively translated into positive child health outcomes.

\subsubsection{Immunization and Child Health}

The National Research Council (1993) reported that, the Expanded Programme on Immunization (EPI), established by the WHO has made major efforts globally in increasing the proportion of children covered by basic immunization vaccines against childhood diseases especially in most African countries. With respect to this, many countries have focused their scarce resources on EPI inventions which there perceived to be cost-effective due to the low level of funding and the basic vaccines on the EPI programme have proven efficacious to varying degrees. However, the efficacy does not necessarily imply that a program based on vaccinations is effective in reducing child mortality. Although child mortality in Africa often results from the interaction of several diseases, which are so complex that it is difficult to estimate the effect of reducing the incidence of a single disease by using mathematical simulations, the WHO \& UNICEF (2009) asserted that immunization remains one of the most important public health interventions to reduce child morbidity and mortality till date.

In an attempt to show the overall prevalence of complete immunization in some African countries, Lakew, Bekele\&Biadgilign (2015), used bivariate and multivariate data analysis methods for Ethiopia DHS data of 2011, for children 12-23 months and showed that the overall prevalence of fully immunized children in Ethiopia was $24.3 \%$ which was quiet low, Chiabi, Nguefack, Njapndounke, Kobela, Kenfack, Nguefack, Mah1, Nguefack-Tsague and Angwafo III (2017) using bivariate and multivariate logistic regression analysis for 400 mothers showed that immunization completeness for children born in the reference hospital of Cameroon capital city was quite high $(96.3 \%)$ but the number of children correctly vaccinated was relatively low (73.3\%).

\subsubsection{Poverty and Child Health}

Poverty is a multi-faceted phenomenon which affects an individual's ability to purchase goods, and services towards various pleasures that may prohibit the individual from enjoying life (Akerele, Momoh, Adewuyi, Phillip\& Ashaolu, 2012). Poverty rate is the percentage of the population living below a given poverty line of an income. Pritchard\& Keen (2016) stated that any debate of social class and mobility would be partial without a discussion of poverty. In relation to poverty and child health, the WHO (2001) reported that children in poor families are sick more often and poverty multiplies the risk of children dying before their fifth birthday. Research on poverty and child development has shown negative influences in different dimensions. For instance, Liu (2016) reviewed the studies of other authors and found out that poverty status and increased number of children's bed days and school absences, and decreased maternal rating of child health are positively correlated. 
Pritchard \& Keen (2016), found a positive significant correlation between higher child mortality rates and relative poverty measures in the West, Asia and Sub-Saharan African regions using spearman rank order correlation. Tegoum, \&Hevi, (2016) asserted that even though poverty is a multidimensional phenomenon, many researchers in Cameroon, still focus only on the monetary aspect and particularly, the issues of poverty and children is ignored. They use a combination of aggregate and poverty line methodology to analyse data from Multiple Indicators Clusters Survey (2006) and found that the incidence of child poverty was $73.4 \%$ with $25.4 \%$ children suffering from extreme poverty. Child poverty here included aspects of child health and nutrition, child welfare and parents affections. Odima (2014) using Kenyan DHS data 2008-09 and two-stage least squares instrumental variable methods in estimating the link between poverty(wealth index) and child mortality showed that poverty, residence type, mothers education, access to water, access to sanitation and source of cooking fuel and gender of household head have significant effect on child mortality rates in Kenya. Child mortality rates are found to decline as wealth index increases.

Hence this study adopted and modified a conceptual framework from Kato, Mugarura, Kaberuka, Matovu and Yawe (2018) to show the relationship between the independent variables (public health expenditure, complete or full immunization coverage rates, poverty rates) and the dependent variable (child mortality rate) based on the Grossman production function.
Independent Variables

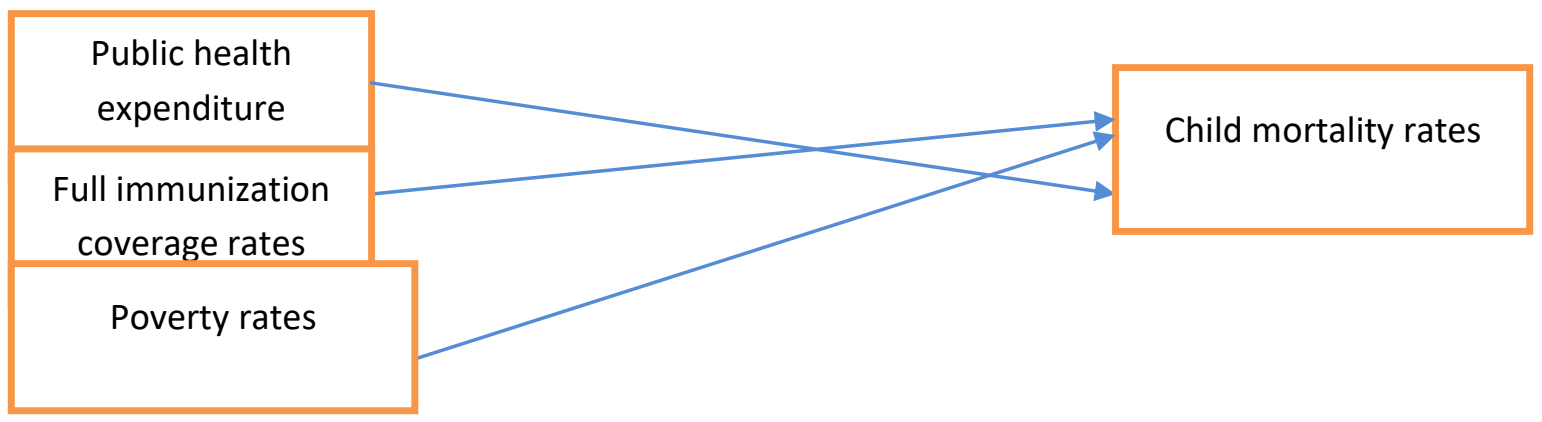

Fig1. Relationship between public health expenditure, full immunization coverage rates, poverty rates and child mortality rates

\subsubsection{Conceptual Framework Adapted and Modified From Kato, Mugarura, Kaberuka, Matovu and Yawe (2018)}

The framework above explains the interconnecting concepts of the variables used in this study. It shows that child mortality is subjective to public expenditure and other determinants. In this case complete immunization coverage rates and poverty rates are used. Increased public health expenditures coupled with optimum complete immunization coverage rates and reduced poverty rates is therefore expected to reduce child mortality hence improving child survival. Further, this framework prevents the challenges of identifying the most cost effective ways for using the limited health sector resources to ensure child survival

\subsection{Empirical Literature}

\subsubsection{Evidence from Other Authors}

Rajkumar\&Swaroop, (2008) reviewed works of other authors and found that the relationship between PHE and CMR is stronger in lowincome countries than in higher-income countries, They went further to prove that this relationship is governance oriented using Ordinary Least Square (OLS) regressions methods, and a sample of 228 observations over three years (1990, 1997 and 2003) from 91 developed and developing countries, with two measures of governance: corruption and bureaucratic quality to interact with public health spending often does not yield the expected improvement in outcomes. The results showed that public health spending has a stronger negative impact on child mortality in countries that have good governance where a $1 \%$ increase in public health spending showed a corresponding $0.32 \%$ decreased in under-5 mortality rate. This effect decreases by $0.20 \%$ in countries with average governance and has no 
effect in countries with weak governance. As the level of corruption falls or the quality of the bureaucracy rises, public health spending becomes more effective in lowering child mortality.

Further to show that public health expenditure has failed to be translated into better health status due to corruption perceptions and governance issues in most developing countries, Yaqub, Ojapinwa, \&Yussuff(2012), investigated the impact of public health spending on infant, under-5 mortalities and life expectancy in Nigeria using country level data from 19802008 and OLS/ two-stage least square analytical methods. The results of the simple version of OLS for the infant and Under-5 mortalities showed that the relationship between public health expenditure and infant and under-5 mortalities were negative but the efficacy of public spending in lowering infant and under-5 mortalities is positively related with the level of governance, which supports the argument for good governance. As the corruption level goes down there is a decline in infant and under-5 mortalities and an increase in life expectancy.

Given the trends of most health outcome variables with the progressive increase in public health expenditures, one might be tempted to conclude that the relationship is positive. But this relationship proves to be region dependent by Anyanwu\&Erhijakpor (2009) who using robust OLS, robust 2SLS examining data from 47 African countries from 1999 and 2004, found a statistically positively significant relationship between PHE and infant and under-5 mortalities for sub-Saharan African countries even though the decline in mortality has been particularly slow where some countries show increase rates of child mortality and a negative relationship for the Northern Africa countries.

Similarly, Issa\&Quattara, (2005), showed that the relationship between public health expenditure and health outcome depends on the economic development of the country. They used OLS and panel data techniques on 160 countries showed a strong negative relation between health expenditure and infant mortality rates(IMRs). This study found that at low levels of development public health expenditures has stronger effect on mortality rates compared with private health expenditures, while in a country of high development levels the opposite is true. In LMICs, PHE was highly significant with a correct negative sign at all levels of regression
(OLS, fix and random effect and dynamic regression) where a $1 \%$ increase in PHE leads to a $0.16 \%$ decrease in IMRs. The given evidence in this regard shows a wide variation of per capital health expenditure and public health expenditure within and between different countries in the world according to their levels of development.

Novignon, Olakojo\&Nonvignon (2012), investigated the effect of public and private health expenditure on population health status using fix and random panel data regression models to analyse a pooled cross section and annual time series data for 44 countries over a period from 1995 to 2010 and the results showed that both public and private health care spending showed strong positive association with health status even though public health care spending had relative higher impact. They found that increase public health care spending reduced infant mortality rate by approximately 4 infants, increased life expectancy at birth by about 1yearand reduced death rate by about 0.8 at $1 \%$ significance level in both models. Likewise (Kim \& Lane 2013), examined the relationship between public health expenditure and health outcome (infant mortality rate and life expectancy at birth) for 17 OECD countries between 1973 and 2000 using a mix model effect over a panel data. The results showed that public health expenditure is a very strong predictor for public health outcomes. The results show that a $1 \%$ increase in public health expenditure decreases infant mortality rate by .077 and increases life expectancy by 0.026 .

\section{MeThOdOLOGY}

This study made use of ordinary least square analytical techniques. However because of the possibility of reverse causality or joint determination of health outcome and public health expenditure, it was re-estimated using two-stage-least-squares (2SLS) method. The result of the OLS is presented and discussed first and this is compared with that of the 2SLS.

\subsection{Theoretical Framework}

The theoretical framework adopted in this study follows from Novignon and Lawanson (2017) but with slight modifications. They developed a macro level health production function based on the Grossman production function of 1972, where individuals use medical care and their own time to produce health. Here, individuals regard health as a commodity to consume and 
maximize subject to his/her budget constraint and depending on other endogenous and exogenous variables which have an impact on an individual's health. According to Grossman, health status is determined by many factors among which is medical care and other factors such as social class, work environment, employment status, and income level, housing conditions, heating, education, diet and lifestyle amongst others.

The basic Grossman production function is: $\mathrm{H}$ $=\mathrm{f}(\mathrm{X})$, Where $\mathrm{H}$ is the health outcome, and $\mathrm{X}$ is a vector of the individual inputs to health production. Adapted in this study, the health status is child mortality rate and the factors that determine it are public health expenditure (PHE), full child immunization coverage rate (FIR) and poverty rates (PR). Thus, our starting model is formulated through a health variable $\mathrm{H}$ that it is an individual's 'true' health which depends on a linear combination of explanatory variables:

$\mathrm{H}=\beta_{0}+\beta \mathrm{X}+\mathrm{U}_{0}$

Where $H$ is the health status, $\beta_{0}$, constant of interception, $X$ is a set of explanatory variables, $\beta$ a set of coefficients and $U_{0}$ an error term.

\subsection{Empirical Model Specification}

The main objective of this paper is to the find out the effect of public health expenditure on child mortality rates in Cameroon. More specifically, we examine the role of complete or full child immunization coverage rate and poverty rates in determining the efficacy of public health spending in improving child mortality rates. With modifications, from the study of Oluwatoyin, Folasade\&Fagbeminiyi(2015), the basic functional form of model for this study is:

$\mathrm{CMR}=\mathrm{f} \quad(\mathrm{PHE}, \quad$ FIR, PR) $\ldots \ldots \ldots \ldots \ldots \ldots \ldots \ldots \ldots \ldots \ldots \ldots$

Putting equation 1 in an estimable form, we have:

$\mathrm{CMR}=\beta_{0}+\beta_{1}(\mathrm{PHE})+\beta_{2}(\mathrm{FIR})+\beta_{3}(\mathrm{PR})+$ $\mathrm{U}_{0}$ ...2

Where CMR $=$ Health outcome (Child mortality rate), $\mathrm{PHE}=$ Public health expenditure (Public), FIR = Full Immunization Coverage Rate and $\mathrm{P}=$ poverty rates and $\mu$ is the error term.

Apriori expectations for equation $2: \beta_{0}<$ or $>0$, $\beta_{1}>0, \beta_{2}>0, \beta_{3}<0$

\subsection{Data Source}

This study made use of country specific time series annual data in a short run from the year 2001-2014 for public health expenditure, complete immunization coverage rates, poverty rates and child mortality rates for Cameroon. The data set used for this study were obtained from UNICEF (2017), WHO (2017), and World Bank (2015). The selection of the data collection period was chosen because of the Abuja declaration of 2001 for WHO states governments to allocate at least $15 \%$ of their annual budget to the health sector, the MDGs (2000) objective to alleviate poverty and improve child health and the Addis Ababa (2006) declaration that acknowledges the relationship between health and poverty alleviation.

\subsection{The Dependent and Independent Variables}

\subsubsection{Dependent Variables}

The choice of child mortality rates as a dependent variable for this study is because child mortality is a developmental indicator for a population and the universal acceptance of children as the future of tomorrow.

\subsubsection{Independent Variables}

The selection of independent variables in this study was guided by the WHO (1999) systematic exercise to develop a health expenditure data for all of its 191 member States with respect to health outcomes and the Abuja (2009) declaration for all WHO member states to allocate $15 \%$ of their budget to the health sector. The UNICEF introduction of EPI, which till date, is one of the most effective global public health interventions to ensure child survival, the Addis Ababa declaration on community health (2006) which acknowledges the relationship between health and poverty alleviation among others and the study of Younger (2001), who identified household income, availability of health services and the vaccination of children as vital factors that impact child survival.

\section{Presentation AND Discussion OF FINDINGS}

\subsection{Descriptive Analysis}

Table 1 below shows the historical behaviour of the underlying variables. Other than PHE, all the other variables are negatively skewed about 
their means. The skewed values for all the variables fall in the range $-1.96-+1.96$ which is the condition for a normal distribution about the mean. Also all other execute negative kurtosis (meaning the tails are lighter than for a normal distribution) but for PHE with a positive kurtosis value (meaning the tail is heavier than Table1. Descriptive Statistics for a normal distribution). The kurtosis values of CMR (-1.281), FIR (-0.114) and PR (-0.861) indicate that these distributions are possibly platykurtic and that for PHE (0.752) indicate a possibility of leptokurtic distribution about the mean.

\begin{tabular}{|c|c|c|c|c|c|c|c|}
\hline & Mean & Std. Deviation & Min. stat. & Max. stat. & Skewness & Kurtosis & N \\
\hline CMR & 121.1 & 17.59 & 93.8 & 147.2 & -0.85 & -1.281 & 14 \\
\hline PHE & 1.17 & 0.16 & 0.94 & 1.51 & 0.752 & 0.064 & 14 \\
\hline FIR & 54.8 & 12.49 & 34.3 & 75.9 & -0.210 & -0.114 & 11 \\
\hline PR & 39.3 & 0.95 & 37.5 & 40.2 & -0.802 & -0.861 & 14 \\
\hline
\end{tabular}

Source: Author's computation (SPSS version 20)

Table2. Pearson Correlation matrix

\begin{tabular}{|c|c|c|c|c|}
\hline & CMR & PHE & FIR & PR \\
\hline CMR & 1.00 & -.287 & -837 & .958 \\
\hline PHE & .287 & 1.00 & -.441 & .308 \\
\hline FIR & -.837 & -.441 & 1.00 & -.744 \\
\hline PR & .958 & .308 & -.744 & 1.00 \\
\hline
\end{tabular}

Source: Author's computation (SPSS version 20)

From the correlation matrix, Child mortality rate (CMR) shows a strong positive relationship with poverty rate (PR) at $95.8 \%$ but has a negative relationship with public health expenditure (PHE) at $-28.7 \%$ (weak) and full immunization coverage rate (FIR) at $-83.7 \%$ (strong).

\subsection{Ordinary Least Squares Estimates}

The result of the ordinary least squares (OLS) analysis shows the relationship between the

Table3a. The unstandardized coefficients and the significant value of the single effect of PHE and CMR

\begin{tabular}{|l|l|l|l|l|l|}
\hline MODEL & COEFFICIENTS & SIG. & $\mathbf{R}^{2}$ & ADJUSTED R & F-STAT \\
\hline 1 & 25.15 & 0.441 & 0.050 & -0.29 & 0.441 \\
\hline
\end{tabular}

Source: Author's computation (SPSS version 20)

Table 3a shows a positive and non-significant relationship between PHE and CMR. It implies

that a $1 \%$ increase in PHE will lead to an estimated 25.15 increase in CMR. variables (public health expenditure, immunization coverage rate and poverty rate) over the study time period. The OLS was done first with PHE only as the independent variable and CMR the dependent variable. And a second analysis done taking into consideration the immunization and poverty rate effect. The results are represented below. dependent (child mortality rate) and independent

Table3b. The unstandardized coefficients and the significant values of the combined effect for the three independent variables

\begin{tabular}{|l|l|l|}
\hline MODEL & COEFFICIENTS & SIG. \\
\hline CONSTANT & -391.93 & 0.005 \\
\hline PHE & -9.32 & 0.370 \\
\hline FIR & -0.49 & 0.040 \\
\hline PR & 14.03 & 0.000 \\
\hline
\end{tabular}

Source: Author's computation (SPSS version 20)

Hence equation 3 becomes:

$\mathrm{CMR}=-391.93+(-9.32) \mathrm{PHE}+(-0.49) \mathrm{FIR}+$ 14.03PR................ 4

From equation 4 , the estimated intercept of the equation $2, \beta_{0}$ is -391.93 . This indicates that, if all explanatory variables become zero (0) or are held constant, the endogenous variable CMR would change by -391.1 .
The estimated slope for the coefficient of public health expenditure (PHE: $\beta_{1}$ ) is -9.32 . This is shows a negative relationship between PHE and CMR as expected. Meaning 1\% increase in PHE would cause CMR to decrease by about $9.32 \%$. This result is in line with the study of Boachie, Ramu\& and Põlajeva (2018) who showed that a $10 \%$ increase in PHE public health expenditure 
prevents 0.102-4.4 infant and under-five deaths in every 1000 live births in Ghana using OLS and 2SLS estimators and the results of Kim \& Lane (2013) who used the linear mix model analyses for cross country panel data for 17 OECD countries and showed that a $1 \%$ increase in PHE led to 0.077 decrease in infant mortality rate.

The estimated slope for the coefficient of immunization coverage rate (FIR: $\beta_{2}$ ) is -0.49 which also indicates a negative relationship between CMR and FIR as expected. Implying for a $1 \%$ increase in FIR, leads to an estimated $0.49 \%$ decrease in CMR, increasing survival chances for children. This is in line with Toby \&Arabi (2018) who used OLS analysis and showed that a $1 \%$ increase in access to DPT vaccine by children in India increased life expectancy by $0.01 \%$ which implies increase in child survival chances, contrarily in the same study, a $1 \%$ rise in access to measles vaccine by children was revealed to reduce life expectancy by $0.02 \%$.

The estimated coefficient for poverty rate (PR; $\beta_{3}$ ) is 14.03. This expresses a positive relationship between child mortality rate and poverty rate. Implying as PR increases, CMR also tends to increase. This is in line with the apriori expectations. The coefficient $\beta_{3}=14.03$ implies that with a $1 \%$ increase in PR, CMR is predicated to be 14.03 units higher. This results is in accordance to Odima (2014), in Kenya who used 2SLS analyses to show that poverty Table4. Model summary (measure of the wealth index), had significant effect on child mortality rates and found that a one unit increase in wealth status (reduction in poverty status) of the rich class resulted into 3.1 units decrease in child mortality.

The significant values $0.000,0.04$ and 0.000 for the constant, complete or full immunization coverage rate and poverty rates are less than the $\mathrm{P}$-value 0.05 . Hence are statistically significant predictors for child mortality rates in Cameroon. As against the significant value for PHE (0.377) which is greater than the P-value 0.05. Hence, PHE is not a statistically significant predictor to CMR in Cameroon. This is in accordance with Toby \&Arabi (2018) who using OLS regression techniques showed that both public and private health expenditures had an insignificant effect on under-5 mortality in India and Byaro and Musonda (2017), using a frequentist and Bayesian model approached showed that the coefficient of PHE was correctly signed but was not significant in reducing child mortality rates factoring in real GDP and improve sanitation in health facilities as other independent variables. But against the results of Boachie, Ramu\& and Põlajeva (2018) who showed that the coefficient PHE was correctly signed and significant in reducing under-5 mortality in Ghana using OLS and 2SLS estimators, and Arthur \&Oaikhenan (2017), who showed that reductions in mortality rates were significantly influenced by public health expenditure in SSA countries.

\begin{tabular}{|c|c|c|c|c|c|c|c|}
\hline Model & $\mathbf{R}$ & $\mathbf{R}^{\mathbf{2}}$ & Adjusted $\mathbf{R}^{\mathbf{2}}$ & Std. error of estimation & $\mathbf{R}^{\mathbf{2}}$ change & F change & Sig F change \\
\hline 1 & $.224^{\mathrm{a}}$ & 0.050 & -0.029 & 17.8389 & 0.050 & 0.636 & 0.441 \\
\hline 1 & $.978^{\mathrm{a}}$ & .957 & .938 & 4.7713 & 0.957 & 52.47 & 0.000 \\
\hline
\end{tabular}

Source: Author's computation (SPSS version 20)

Table 4 above shows the model summary of the two OLS analyses. Row 1 shows the results of CMR as the dependent variable and PHE as the independent variable, and row 2 shows PHE and CMR, incorporating the impact of full immunization coverage rate and poverty rates. Considering row-2, the $\mathrm{R}^{2}$ value of 0.957 indicates that $95.7 \%$ of the variation in CMR can be predicted by PHE, FIR and PR. This overall measure of the strength of association is highly statistically significant with an F-static of 0.000 , and does not reflect the extent to which any particular independent variable is associated with the dependent variable. Considering row-1, the F-statistic (0.441) of the single effect of PHE on CMR is statistically not significant. This is in accordance with Muthaka (2013) who got negative but non-significant effects for all measures of child health when household and government health expenditure effects on child health were separately analyzed, but a zero Fstatic valued confirming the joint effect of the complementary role between private and government investments in improving child health in Kenya using linear probability and control function models.

\subsection{Stage Least Square Analysis}

The two stages least square analysis reported on table $5 \mathrm{a}$ and $5 \mathrm{~b}$ below confirms the results obtained from the OLS analysis above. 
Public Health Expenditure and Child Mortality Rate as Determinants of Full Immunization Coverage and Poverty Rates in Cameroon

Table5a. Unstandardized Coefficients of the basic equation without the immunization and poverty rates effect

\begin{tabular}{|c|c|c|c|c|c|c|c|c|}
\hline \multicolumn{2}{|c|}{} & B & Std. Error & Beta & t-value & Sig. & R $^{2}$ & Adjusted R \\
\hline \multirow{2}{*}{ Equation 1 } & (Constant) & 91.737 & 37.120 & & 2.471 & .029 & 0.05 & -0.029 \\
\cline { 2 - 9 } & Expenditure & 25.152 & 31.541 & .224 & .797 & .441 & & \\
\hline
\end{tabular}

Source: Author's computation (SPSS version 20)

Table5b. Unstandardized Coefficients of the 2SLS analysis with the immunization and poverty rate factors

\begin{tabular}{|c|c|c|c|c|c|c|c|c|}
\hline \multicolumn{2}{|c|}{} & B & Std. Error & Beta & t-value & Sig. & R $^{2}$ & Adjusted R \\
\hline \multirow{4}{*}{ Equation 1 } & (Constant) & -389.961 & 95.106 & & -4.100 & .005 & 0.957 & 0.939 \\
\cline { 2 - 9 } & expenditure & -9.371 & 9.774 & -.083 & -.959 & .377 & & \\
\cline { 2 - 9 } & immunization & -.497 & .193 & -.318 & -2.571 & .040 & & \\
\cline { 2 - 9 } & Poverty & 13.990 & 2.189 & .746 & 6.390 & .000 & & \\
\hline
\end{tabular}

Source: Author's computation (SPSS version 20)

\section{Discussions}

Notwithstanding the insignificant effect of PHE, the unstandardized coefficients behaved according to apriori expectations. The results of the OLS and 2SLS analysis for the combined effect showed that, the coefficient for PHE is correctly signed but not significant in reducing child mortality rates over the time period in this study. This could be as a result of the fact that PHE favors the better off than the poor, and $40 \%$ of the Cameroonian population is living below the poverty line (World Food Program, 2018) and over the last 7 years, health sector spending has not been a priority in Cameroon's budgeting decisions (Cameroon Public Expenditure Review, 2018). Aligning public health expenditures with the Vision 2035 goals, the review suggested that a number of inefficiencies exist in the Cameroon health sector which may be reasons why an increase in public health expenditure only, does not significantly translate into reducing child mortality rates.

In 2016, the total health expenditure in Cameroon rose to about $40 \%$ with household out-of-pocket payments which is the main source of health care financing in Cameroon accounting for about $60 \%$ of the total health expenditure. This has left many Cameroonians leaving below the national poverty line. However, with a rapid population growth, this has translated to a per capita rise of about $20 \%$ only. Over the same period, there was a decline of about $0.4 \%$ of the total health expenditure as a share of GDP averaging $4.7 \%$ in 2016, which is lower than the regional average of $5.6 \%$ of GDP. In 2015, with available data from 52 African countries, Cameroon had the third highest level of out-of-pocket spending relative to total health spending behind Nigeria and Equatorial Guinea. Government spending on health which is about $23 \%$ of the total health expenditure is low and declining as a share of the total national budget and public spending on health as a proportion of total health expenditure and GDP $(0.9 \%)$ remains one of the lowest in Africa. As a share of the general government expenditure, public health spending has fallen from $6.2 \%$ in 2010 to an estimated $5.2 \%$ in 2016. This is much lower than the average for lower middle-incomes of $14 \%$ and falls short of the $10 \%$ and $15 \%$ WHO recommendation and the Abuja commitment.

\section{Concluding REMARKS}

Summarily, over the years, child mortality has been a global problem. In the last decade, there has been a global decline in child mortality rates with significant progress made by many developed countries. Unfortunately this has not been the case in most LMICs. Many factors are said to cause variations in the child mortality rates over years. Hence, this paper investigates the relationship between public health expenditures and child mortality (under-5 mortalities) in Cameroon over the period of 2001-2014 taking into consideration the effect of full immunization coverage rates and poverty rates in the same study period using ordinary least square regression analytical methods and two stages least square analysis because of the likelihood of reverse causality. The analysis shows that PHE has a negative and insignificant effect on CMR negative when complete immunization and poverty rates are included. The combine effect of complete immunization, poverty rate and public health expenditure is highly significant in reducing child mortality rates in Cameroon.

The findings of this study clearly suggest that just increasing public spending alone is not going to improve health status of children in Cameroon unless certain factors like the rate of 
full immunization coverage and poverty are addressed. It could be concluded that despite the relationship between under-5 mortality and many other possible determinants, one of the most important factor relevant to under-5 mortality in Cameroon is complete immunization for children and poverty rates. Hence PHE can be translated into improve child mortality rates if other influencing determinants are addressed.

\section{RECOMMENDATIONS}

The policy implication of the findings is that achieving the Sustainable Development Goal of lowering child mortality to at least as 25 per 1,000 live births in Cameroon may be unachievable if there are no considerable nationwide improvements in levels of full immunization coverage rate and reduction in poverty rates. Recommendable, public policy may play a role in improving the effectiveness with which public health expenditures are transformed into better health for children. The development of children's health and outcomes follows a social gradient with better outcomes registered in the upper socioeconomic spectrum. Hence, national and international policies for societal and individual empowerment in improving socioeconomic status of the society will be a plus to the child mortality figures in Cameroon. There is need for a political will and service system that truly prices children as the future of tomorrow to work collectively to ensure child survival.

\section{REFERENCES}

[1] Akerele, D., Momoh, S., Adewuyi, A.S., Phillip, B. B., \&Ashaolu, F.O. (2012) "Socioeconomic determinants of poverty among urban households in South-West Nigeria" International Journal of Social Economics, $39(3)$ : 168-1181, https://doi.org/10.1108/ 03068291211199341.

[2] Anyanwu, J.C., \&Erhijakpor, O.A. (2009).Health expenditures and health outcomes in Africa. African Development Review, 21(2):400-434.

[3] Arthur, E., \&Oaikhenan, H. (2017). The Effects of Health Expenditure on Health Outcomes in Sub-Saharan Africa (SSA): The Effects of Health Expenditure. African Development Review. 29. 524-536. 10.1111/14678268.12287. (Abstracted).

[4] Boachie, K.M., Ramu, K., and Põlajeva, T (2018).Public health expenditures and health outcomes: New evidence from Ghana. Economies, MDPI, Open Access Journal, 6(4):1-25, October.
[5] Byaro, M., \&Musonda, P. (2017). Per capita income and public health expenditure: what makes good child health outcomes in Tanzania? a comparison of Frequentist and Bayesian approach (1995-2013). International Journal of Health, 5(1):74-81.

[6] Chiabi A., Nguefack, F., Njapndounke, F.,Kobela, M., Kenfack, K, Nguefack, S., Mah, E., Nguefack-Tsague, G. \&FruAngwafo III, F. (2017). Vaccination of infants aged 0 to 11 months at the Yaounde Gynaeco-obstetric and pediatric hospital in Cameroon: how complete and how timely? BMC Pediatrics 17:206. doi 10.1186/s12887-017-0954-1.

[7] Compah-Keyeke, G., Sackey, G. F., \&Azinim, A.A. (2013).Public expenditure and health status in Ghana. Journal of Economics and Sustainable Development, 4 (11), ISSN 22221700 (Paper) ISSN 2222-2855 (Online).

[8] Franz, J., \&Fitzroy, F. (2006).Child Mortality and Environment in Developing Countries. Epidemiology, 27(0518). DOI:10.1007/s11111 - 006-0020-7.

[9] Grossman, M. (1999).The Human Capital Model of the Demand for Health. The National Bureau of Economics Research. Working Paper No. 7078. Doi: 10.3386/w7078. Retrieved from https://www.nber.org/papers/w7078.pdf.

[10] Issa, H., \&Ouattara, B. (2005). The effect of private and public health expenditure on infant mortality rates: does the level of development matters? Damascus Univ. J. 28.

[11] Kato, K., Mugarura, A., Kaberuka, W., Matovu, F., \&Yawe, L.B. (2018).The effect of public health spending on under-five mortality rate in Uganda. African Journal of Economic Review, 4(1).

[12] Kulkarni, L. (2016). Health inputs, health outcomes and public health expenditure: Evidence from the BRICS Countries. International Journal of Applied Economics, 31(1):72-84.

[13] Lakew, Y., Bekele, A., \&Biadgilign, S. (2015). Factors influencing full immunization coverage among 12-23 months of age children in Ethiopia: evidence from the national demographic and health survey in 2011. BMC Public health 15:728.DOI 10.1186/s12889-0152078-6.

[14] Liu, Y. (2016).The Effects of Poverty on Children Development. Retrieved from https://behavioraldevelopmentblog.wordpress.com

[15] Maruthappu, M., Bonnie, Y.K., Williams, C., Atun, R., \&Zeltner, T. (2014).Government health care spending and child Mortality. Pediatrics, 135 (4). doi: 10.1542/ peds.20141600. 
[16] Muthaka, I.D. (2013) Health expenditures and child mortality: Evidence from Kenya (Doctoral thesis, The University of Nairobi, Kenya). Retrieved from https://pdfs.semanticscholar.org.

[17] National Research Council. (1993). Immunization coverage report

[18] Ndedi, A., Metha, A., \&Nisabwe, F. (2017).The Impact of Health Expenditures on Economic Growth of Cameroon: A Literature Review Perspective. Available at http://dx.doi.org/ 10.2139/ssrn.3036510. (Abstracted).

[19] Novignon, J., \&Lawanson, O.A. (2017).Health expenditure and child health outcomes in SubSaharan Africa.African Review of Economics and Finance, 9(1). ISSN 2042-1478.

[20] Novignon, J., Olakojo, A. S., \&Nonvignon, J. (2012). The effects of public and private health care expenditure on health status in subSaharan Africa: New evidence from panel data analysis. Health Economics Review, 2 (22).

[21] Odima, A. O. (2014). Exploring poverty health linkages: A case of child mortality in Kenya.(Master thesis, University of Nairobi).

[22] Oluwatoyin M. A., Folasade B. A., \&Fagbeminiyi, F. (2015) Public health expenditure and health outcomes in Nigeria. International Journal of Financial Economics, 4 (1): 45-56.

[23] Pacific Prime. (2019). Simplifying insurance units 5-11, 35th Floor, One Hung to Road, Kwun Tong, Hong Kong

[24] PJ, \&Hevi, KD (2016). Child Poverty and Household Poverty in Cameroon: A Multidimensional Approach. Poverty and Wellbeing in East Africa; 11-33. DOI: 10.1007/ 978-3-319-30981-1_2

[25] Poullier, J-P., Hernandez, P., Kawabata, K., \&Savedoff, D.W. (2002). Patterns of Global Health Expenditures: Results for 191 Countries. World Health Organization, Discussion Paper No. 51 EIP/HFS/FAR. Retrieved from https://www.who.int/healthinfo/ paper51.pdf.

[26] Pritchard, C., \& Keen, S. (2016). Child mortality and poverty in three world regions (the West, Asia and Sub-Saharan Africa) 19882010: Evidence of relative intra-regional neglect? Scandinavian Journal of Public Health, 44(8): 734-741. https://doi.org/10.1177/ 1403494816675550 (Abstracted).

[27] Rajkyman, A.S. \&Swaroop, V. (2008). Public spending and outcomes: Does governance matter? Journal of Development Economic, 86: 96-111.

[28] Tae, K.K. \& Lane R.S. (2013). Government Health Expenditure and Public Health Outcomes: A Comparative Study among 17 Countries and Implications for US Health Care
Reform. American International Journal of Contemporary Research, 3(9).

[29] Toby. J.K, \&Arabi, U. (2018).The effect of health expenditure on health outcomes at the macro level: The Indian experience. Innovative Journal of Business and Management, 7 (6):143-150. http://www.innovativejournal.in/ index.php/ijbm

[30] UNICEF \& WHO. (2009). State of the world's vaccines and immunization. $3^{\text {rd }}$ ed. Geneva: World Health Organization; 2009.

[31] UNICEF (2017), Under-5 mortality data for Cameroon.

[32] UNICEF. (2013). Committing to child survival: A promise renewed progress report 2013. Retrieved from https://www.unicef.org/ publications/files/APR_Progress_Report_2013 _9_Sept_2013.pdf.

[33] UNICEF. (2016). UNICEF Annual Report 2016-Cameroon. Retrieved from https://www.unicef.org/about/annualreport/file/ Cameroon_2016_COAR.pdf.

[34] UNICEF. (2018). Levels and Trends in Child Mortality. Retrieved from https://www.unicef.org/publications/index_103 264.htm.

[35] UNICEF.(2018). Monitoring the situation of children and women. Retrieved from https://data.unicef.org/topic/child-health/ immunization

[36] Victorino, C.C. \& Gauthier, H.A (2009). The social determinants of child health: variations across health outcomes - a population-based cross-sectional analysis BMC Pediatrics, 9:53 doi: 10.1186/1471-2431-9-53.

[37] WHO (2010). The Abuja Declaration: Ten Years On. http://www.who.int/whr/2010/ en/index.html.

[38] WHO (2017). Public health expenditureCameroon.

[39] WHO. (2001). Better health for poor children. A Special report from the WHO/World Bank Working Group on Child Health and Poverty.

[40] WHO. (2012). Discussion paper: Positioning health in the Post-2015 development agenda. Retrieved from https://www.who.int/ millennium_development_goals/post2015/WH Odiscussionpaper_October2012.pdf

[41] WHO. (2014). Health and development report. Retrieved from https://www.who.int/ maternal_child_adolescent/child/en/.

[42] WHO. (2017). Immunization coverage. Retrived from https://www.who.int/newsroom/fact-sheets/detail/immunization-coverage.

[43] WHO. (2017). The Addis Ababa declaration on community health in the African Region, 2006. 
Retrieved from https://www.afro.who.int/sites/ default/files/201705/AddisAbabaDeclaration.pdf

[44] WHO. (2018). WHO country cooperation strategy at a glance: Cameroon. Retrieved from https://who/ccu/18.02/Cameroon

[45] World Bank (2015). Poverty head count ratio data-Cameroon

[46] World Bank (2018).Global financing facility. Health care expenditure 2017/2018 annual report. Retrieved from https://www.globalfinancingfacility.org/sites/gf f_new/GFF-Annual-report/republic-ofcameroon.

[47] World Bank (2019). Overview of global poverty. Retrieved from https://www.worldbank.org/en/ topic/poverty/ overview.

[48] World Bank. (2018). Cameroon - Public Expenditure Review: Aligning Public Expenditures with the Goals of Vision 2035 (English).Washington, D.C.: World Bank
Group. http://documents.worldbank.org/ curated/en/501141543353309471/Aligning-

Public-Expenditures-with-the-Goals-of-Vision2035

[49] World Bank. (2019). Public health expenditure data-Cameroon

[50] World Food Programme. (2018). Cameroon country brief. Retrieved from https://www.wfp.org/ countries/cameroon

[51] Yaqub, J.O, Ojapinwa T.V., \&Yussuff R.O. (2012). Public health expenditure and health outcome in Nigeria: The impact of governance. European Scientific Journal, 8(13), ISSN: 1857 -7881 .

[52] Younger .S.D. (2001). Cross country determinants of decline in infant mortality growth regression approach. (Cornel Food and Nutrition Policy Program) working paperno 130, cornel university.

Citation: Promise Aseh Munteh, Alyce Fri Fonchin. Public Health Expenditure and Child Mortality Rate as Determinants of Full Immunization Coverage and Poverty Rates in Cameroon. ARC Journal of Clinical Case Reports. 2020; 6(1):17-30. doi:dx.doi.org/ 10.20431/2455-9806.0601005.

Copyright: (C) 2020 Authors. This is an open-access article distributed under the terms of the Creative Commons Attribution License, which permits unrestricted use, distribution, and reproduction in any medium, provided the original author and source are credited. 